This item was submitted to Loughborough's Research Repository by the author.

Items in Figshare are protected by copyright, with all rights reserved, unless otherwise indicated.

\title{
Emotional and behavioural difficulties of children and young people at entry into care
}

PLEASE CITE THE PUBLISHED VERSION

http://dx.doi.org/10.1177/1359104507088344

PUBLISHER

(c) SAGE Publications

VERSION

AM (Accepted Manuscript)

\section{PUBLISHER STATEMENT}

This work is made available according to the conditions of the Creative Commons Attribution-NonCommercialNoDerivatives 4.0 International (CC BY-NC-ND 4.0) licence. Full details of this licence are available at: https://creativecommons.org/licenses/by-nc-nd/4.0/

\section{LICENCE}

CC BY-NC-ND 4.0

\section{REPOSITORY RECORD}

Sempik, Joe, Harriet Ward, and lain T. Darker. 2019. "Emotional and Behavioural Difficulties of Children and Young People at Entry into Care". figshare. https://hdl.handle.net/2134/15886. 


\section{Emotional and Behavioural Difficulties of Children and Young People at Entry into Care.}

Joe Sempik $^{1}$, Harriet Ward ${ }^{2}$ and lain Darker ${ }^{3}$

Centre for Child and Family Research, Department of Social Sciences, Loughborough University, Leicestershire LE11 3TU.

( ${ }^{1}$ Research Fellow, Centre for Child and Family Research and author for correspondence; ${ }^{2}$ Professor of Child and Family Research and Director of the Centre for Child and Family Research; ${ }^{3}$ Research Associate, Applied Vision Research Centre, Loughborough University)

[Word count, excluding tables, abstract and references - 4768] 


\begin{abstract}
.
Emotional and behavioural difficulties of a sample of children and young people were identified at the point of entry to local authority care by analysis of social work case files. The files indicated high levels of need, including that in children aged under five.
\end{abstract}

Bedwetting was identified as an important issue related to the physical health and emotional well-being of looked after children. There was an association between bedwetting and emotional and behavioural problems. Analysis of placement types at entry to care showed that significantly more boys than girls were first placed in residential care.

\title{
Keywords
}

Looked after children; local authority care; emotional difficulties 


\section{Introduction.}

Children and young people who become looked after by local authorities are among the most vulnerable and disadvantaged members of society. A high proportion have been abused and neglected, with potentially long-term consequences for their future well being (Frame, 2002; Moe \& Slinning, 2003; Packman \& Hall, 1998). They may also have missed out on their education and failed to access adequate health care (Jackson, 2001; Ward, Jones, Lynch, \& Skuse, 2002). Many of them will have experienced frequent changes of household, domicile, primary carer and school while living with their families (Ward, Munro \& Dearden, 2006). There is increasing evidence that $70-80 \%$ of the children who enter care in England have extensive needs that require a highly skilled, professional service if satisfactory outcomes are to be achieved (see Ward, Holmes, Soper \& Olsen, forthcoming; Skuse \& Ward, 2003). Particular concerns have been raised about the prevalence of emotional and behavioural difficulties among care populations (see Quinton \& Murray, 2002, for overview). Previous studies have shown that these can be high, and that difficulties may be compounded by adverse experiences while looked after (see Quinton \& Murray, 2002; Jackson \& Thomas, 1999).

New guidance on the health care of looked after children (Department of Health, 2002) was issued to local authorities in 2002 as part of the 'Quality Protects' initiative. The guidance aimed to address the issues relating to the health and well-being of looked after children. Local authorities are now required to undertake more comprehensive holistic assessments of their health care needs, and measures are in place to ensure that Primary Care 
Trusts are informed of placement changes. A National Healthy Care Standard has been developed and a comprehensive Healthy Care Programme put in place to provide a practical means of improving the health of looked after children in line with the new guidance (National Children's Bureau, 2005). The standard defines the requirements for a healthy care environment so that looked after children and young people can achieve the five outcomes identified as the key factors that underpin the current policy initiative, Every Child Matters (HM Treasury, 2003, Department for Education and Skills, 2004, 2007), for all children. The recent White Paper on looked after children, Care Matters: Time for Change, promises to take these issues forward; ensuring that the new 'Joint Strategic Needs Assessment' has a focus on children in care; updating the guidance for promoting the health of looked after children and making it statutory for health care bodies as well as local authorities, and improving measures to promote the positive mental health of children in care (Department for Education and Skills, 2007).

However, while efforts are undoubtedly being made to improve the quality of care for looked after children, there needs to be a greater acknowledgement of the extent and nature of their needs. This paper contributes to the debate by exploring the emotional and behavioural needs of a large population of children looked after by six authorities at entry to care. It demonstrates the need for a formal assessment of emotional well-being at the point of entry, for the data show that a high proportion of this population will require intensive, highly skilled support if their needs are to be met. 


\section{The Study}

This paper explores the data on the emotional difficulties of a sample of children at entry to care and compares the findings with normative data from the general population (Meltzer, Gatward, Goodman \& Ford, 2000) and with data on the mental health of children and young people looked after by local authorities in England (Meltzer, Corbin, Gatward, Goodman \& Ford, 2003). It is important to note that this study was able to examine the needs of children at the point of entry into care, in contrast to that of Meltzer et al. (2003) which looked at the health of children already in care. Another important difference between this study and that of Meltzer et al. (2003) is that whilst Meltzer and his colleagues used diagnostic criteria based on ICD10 and DSM-IV to identify mental disorders from interview and questionnaire data, this study explores information on emotional and behavioural problems, as recorded by social workers and subsequently assessed by psychologists (see below). The threshold was that such problems were 'of concern to current or previous carers', an important practice issue, given the evidence that children's emotional or behavioural problems play a major part in placement disruptions (see Berridge, 1997; Ward et al., forthcoming).

\section{Method}

The data presented in this paper were collected as part of a wider study, the purpose of which was to discover what information local authorities need to monitor the effectiveness of services for looked after children, identify where improvements can be made and decide how scarce resources can be better deployed. A secondary aim was to discover how data gathered through the 
implementation of the Looking After Children materials could be used to address this issue (see Ward, 2004).

The Looking After Children assessment and recording system was intended to guide social workers to ask important questions, based on research evidence about how they could best promote the well-being of children in public care. It was launched in 1995 (Ward, 1995) and, with considerable pressure from government, implemented in virtually all councils in England and Wales. It now forms part of the Integrated Children's System an electronic recording system for assessment, planning, intervention and review, that authorities were required to implement by January 2007 (see Department for Children, Schools and Families, 2007). It was anticipated that the relevant information would be present on social work case files, recorded in a structured format, following implementation of the Looking After Children materials (1995-1998) - in fact, one of the aims of the wider study was to explore whether appropriate data were now present on case files and could be aggregated and used for strategic planning purposes.

In the course of this wider study, data were collected from the case-files of 648 children looked after by six local authorities. Criteria for inclusion were that all children entered the care of the authorities between $1^{\text {st }}$ April 1996 and $30^{\text {th }}$ September 1999, and remained looked after for at least one year. Data were collected retrospectively from case files at entry to care, and subsequently at annual intervals. Children admitted before $1^{\text {st }}$ April 1997 were followed for three years after entry to care; those admitted after $30^{\text {th }}$ 
September 1998 were followed for one year (see Skuse, Macdonald, \& Ward, 2001; Skuse \& Ward, 2003; Ward \& Skuse, 1999, Ward, 2004). Of the 648 children and young people whose case files were examined, 453 (264 boys and 188 girls) had not been previously looked after and their data are presented here. Their ages ranged from 0 to 16, although there were only eight young people aged 16 and these are not included in any analyses by age group. Children in Need (CIN) categories used by authorities to classify each child's needs (Department of Health, 2001) were used in the analysis to identify those who had entered care primarily as a result of abuse or neglect.

The six authorities were selected in order to be as representative as possible of the national population of children looked after away from home. The authorities included inner and outer London boroughs, shire counties, a metropolitan district and a unitary authority and were spread across the country.

The format through which practitioners were required to record information considered necessary for foster carers at the start of a placement included the question: "Does the child display any behaviour patterns that have been of concern to current or previous carers?" (Looking After Children, Placement Plan, Part One, Question 10) (Department of Health, 1995). Emotional and behavioural problems were deemed to be present if this question was answered in the affirmative. The question also asked for further explanation if such problems were thought to be present; these qualitative data were used to compile short pen portraits of each child. Further data concerning the nature of identified behaviour problems and their manifestations were 
collected through scrutiny of Assessment and Action Records (structured formats designed to assess progress, and one of the key elements of the Looking After Children system) and case notes and added to the pen portraits. Behaviour problems were classified as follows:

- Conduct problems (lying, defiance, temper tantrums, absconding)

- Self-harming behaviour (cutting, scratching, eating disorder, substance abuse)

- Inappropriate sexual behaviour (precocious sexualised behaviour, prostitution)

- Relationship problems (has difficulties forming trusting relationship with others)

- Anxiety or depression

- Bedwetting (often a major issue for children and their carers)

- Concentration problems

- Other

These are not always clinical diagnoses of specific disorders, although they do include such conditions when identified by appropriate health professionals and recorded in the case files. Information on behavioural and emotional problems of children under five is also included in the present study. Our classification of conduct problems, for instance, is based on a pragmatic assessment of serious difficulties that might impact on the stability of the placement and the child's future life chances, perhaps through exclusion from school. The Looking After Children programme was introduced because it was thought at the time that social work practitioners would not have sufficient 
skills to complete standardised psychometric tests, and that few local authorities would have staff with the relevant expertise (Ward, 1995). The data presented here, therefore, represent an assessment of the children conducted by trained social care professionals, carried out during the course of standard service provision and are an evaluation of the difficulties experienced by those children within that context. Data from the completed forms and case files were extracted by two psychologists, working closely together, who compiled the pen portraits and made the assessments of emotional or behavioural problems. The Chi-Square and Mann-Whitney U-test were used for testing statistical significance and the level of significance was set at $p<0.05$. 


\section{Emotional and behavioural problems.}

Table 1 compares the incidence of emotional and behavioural problems identified in this study with mental and behavioural disorders present in the general population and in a sample of looked after children. Seventy two percent $(72.3 \%)$ of looked after children aged five to fifteen in the present study showed indications of behavioural or emotional problems; $50.2 \%$ showed indications of conduct problems and $22.9 \%$ emotional problems. The prevalence of such problems was far higher than the incidence of emotional or behavioural disorders in the general population; and higher, also, than the incidence of such disorders reported in a sample of looked after children (Meltzer et al, 2003). The higher incidence of emotional and behavioural problems reported in this study, compared with that observed by Meltzer et al (2003), is likely to be due (in part at least) to differences in methodology between these studies. This is discussed later.

[Table 1 here]

The influence of age and gender on mental and behavioural problems.

Not unexpectedly, the incidence of emotional problems was lowest (5.1\%) in the lowest age group (birth to four). Slightly more children in the 11-15 age group were reported to have emotional problems (26.1\%) than those aged five to ten (19.1\%) although this difference was not statistically significant. There was little difference in the number of boys with emotional problems in the older age group (20.3\%) compared with those aged five to ten years (17.7\%). 
Among girls, there was a higher incidence of emotional problems in the older, 11-15, age group (33.3\%) compared with the younger one (22.2\%). However, this difference was also not statistically significant (see Table 2). Of children and young people aged five to fifteen, girls and young women seemed more likely to suffer emotional problems than boys and young men (29.2\% vs 19.0\%) but again the difference was not significant. In the general population the prevalence of emotional problems or disorders is lower and no appreciable gender based differences were reported by Meltzer et al (2000), instead the overall pattern was for the prevalence of emotional difficulties to increase with age.

In contrast to indications of emotional problems, those of conduct problems were more prevalent in boys and young men (37.5\%) at entry into care than among girls and young women $(21.8 \% ; p=0.000 ; n=452)$ (see Table 2). Excluding the youngest age group, there was little change with age in boys, but a marked and statistically significant $(p=.004)$ increase in girls and young women so that in the 11-15 age group the incidence of conduct problems for girls and young women (51.7\%) approached that for boys and young men (54.1\%). Meltzer et al (2003) has also observed a rise in conduct disorder among girls in the 11-15 age group but this was less pronounced than that seen in the present study and appeared to trail off as the girls got older. The present sample had no one over the age of 16 years of age at entry into care and too few at 16 to provide any information about the prevalence of conduct problems in an older age group.

[Table 2 here] 
The types of behaviour exhibited by girls between five and 10 years of age who were identified as having emotional problems were variable. Some were described in case notes as being "flat" or "withdrawn", "expressing phobic behaviours" or being an "anxious child". Others wet the bed or soiled and even smeared; one seven year old was described as using defecation as a "weapon". Other reported behaviours include stealing, lying, inappropriate sexual behaviour and physical and verbal aggression. Some of the children were described as exhibiting very extreme and bizarre behaviour. For example, one girl aged eight was reported as making animal noises and shaking uncontrollably when touched. When in care, she would remove her clothes when angry and also exhibited precocious sexual behaviour at the age of 10 .

\section{Behavioural problems in the under-fives.}

Epidemiological research has tended to focus on the incidence of mental health and emotional disorders and problems in older children and there is little available data on the prevalence of such problems in very young children (under five) who are looked after. Difficulties in methodology for producing specific and reliable diagnoses may account for this lack of data. However, the pragmatic approach used in this study shows that $18.9 \%$ of looked after children below the age of five (19.3\% of boys and $17.4 \%$ of girls) showed signs of emotional or behavioural problems (see Table 2). Further, $14.7 \%$ of children aged three years of age or under showed such problems. The following examples illustrate how these problems may present in the very young. 
A boy aged two was described as verbally and physically aggressive, exhibiting "wild" behaviour. His mother was unable to provide adequate care and his father was accused of physical abuse. By the age of six the boy went on to self-harm and to become physically aggressive towards others, particularly threatening his female foster carer. This, alongside activities such as smearing faeces, brought his foster care placement to an end.

A boy aged four was described as being 'very challenging', he would pick up cigarette ends from the street and would try and smoke them if he could find matches; he was fascinated by fire and would try to start fires. Although he appeared happy at nursery he could be aggressive towards other children.

These examples show that very young children do have recognisable emotional problems that can be identified from case records. Further, the problems can become increasingly serious as the child grows older and may disrupt placements, particularly where conduct problems are a factor. Indeed, showing violent behaviour towards others or animals (activities associated with conduct disorder) has been reported to be associated with extremely poor outcomes for looked after children, often leading to an unstable care career and failure to find a permanent adoptive placement (Selwyn, Sturgess, Quinton \& Baxter, 2003). 


\section{Bedwetting in looked after children.}

Because of the possible impact on emotional well-being and behaviour, the issue of bedwetting in looked after children has been addressed here. Such data have also been collected by Meltzer et al. (2000). Results from this study showed that a substantial number of looked after children aged five or over wet the bed (17.9\%); of children in the 11 to 15 year age group, $15.2 \%$ wet the bed. Bedwetting is far more common among looked after children and young people than in the general population where around $5 \%$ wet the bed (see Meltzer et al. 2000). In the present study, of those aged five or over, children who wet the bed $(n=46)$ were all reported to have indications of emotional and behavioural problems compared with $66.7 \%$ of those who did not $(n=$ 209; $p=.000$ ). A similar pattern was observed in terms of conduct problems; those who wet the bed $(n=46)$ were more likely $(p=.000)$ to show indications of problems $(65.2 \%$ vs $34.8 \%)$ than those who did not $(n=209)$. Further, in the 11 to 15 year old age group, those who wet the bed $(n=20)$ were more likely $(p=.013)$ to have entered care in response to abuse or neglect (based on the Child in Need category assigned to each child or young person) compared with those who did not (60.9\% vs $40.7 \% ; n=112)$. No significant association was found in either the birth to four years or five to 10 years age groups.

[Table 3 here]

\section{Behavioural and emotional problems and the first placements of children and young people entering care.}

Of the total sample of 453 children, significantly $(p=0.001)$ more boys than girls were given a first placement in residential care. There were 49 boys and 14 girls first placed in residential care, including18 boys and one girl aged ten or under. 
For their first placements, children with conduct problems $(n=140)$ were less likely $(p=0.013)$ to be placed in foster care $(60.7 \%$ vs $72.4 \%)$ than those without $(n=312)$; more likely $(p=0.000)$ to be placed in residential care (27.1\% vs $8.0 \%)$ and just as likely to be placed with their parents, although such numbers of placements were small (11.4\% vs $12.5 \%)$. There were nine boys aged 5-10 years with conduct problems in residential care but no girls from the same age group.

Children with any emotional and behavioural problems $(n=222)$ were more likely $(p=0.000)$ to be placed in residential care $(23.0 \%$ vs $5.2 \%)$ than those without $(n=231)$; less likely $(p=0.003)$ to be placed in foster care $(62.2 \%$ vs $75.2 \%)$ and slightly more likely to be placed with parents (54.5\% vs $45.5 \%)$ although this difference was not significant. Whilst a first placement in residential care may often be in response to an emergency and hence act as a 'holding position' prior to a more permanent solution, these data suggest that there may also be a level of planning and assessment for such placements as more children who have recognised emotional and behavioural problems are placed in residential care.

\section{Discussion}

The pragmatic approach to identifying emotional and behavioural problems described here may yield a higher incidence than studies which have adopted stricter criteria (such as Meltzer et al. 2003) to record disorders but may provide a realistic assessment of the incidence of such problems (as distinct from clinically diagnosed disorders) which do cause difficulties to both carers 
and the children concerned (or are likely to cause difficulties in the future). The incidence of all mental and emotional disorders observed by Meltzer et al (2003) among looked after children was $46 \%$ as opposed to the $72 \%$ of children and young people with behavioural and emotional problems seen in this study. However, other research suggests that the incidence of mental health problems among looked after children may be higher than that of disorders. For example, Stanley, Riordan and Alaszewski (2005) reported that $82.5 \%$ of a sample of 80 looked after children had been referred for specialist assessment for mental health needs but that a formal diagnosis had been entered onto the children's records in only 28 cases.

The method used in this study may provide a useful estimate of the number of children entering care for the first time who are likely to have emotional and behavioural needs that may require specialist intervention and/or highly skilled carers. This figure may hitherto have been underestimated but is reflected in the need for specialist services for looked after children. The absence of a specific diagnosis by a trained practitioner or clinician does not necessarily mean the absence of a problem.

Additionally, indications of emotional or behavioural difficulties were identified in almost a quarter of children aged under five at entry into care. There is little data on the incidence of mental health disorders in this group because of diagnostic and assessment difficulties. However, results from this study show that this is an area for concern and more research is necessary. More research would also be valuable in order to assess the overall level of mental 
health problems in very young children in the general population. Although there are methodological difficulties relating to accurate diagnosis of mental ill health in very young children, a pragmatic approach to identifying those young children with mental health needs could prove useful for targeting appropriate services and strategies.

This study looked at the incidence of mental health problems at the point of entry into care and inasmuch differed from the ONS study (Meltzer et al., 2003) which took a snapshot of children already in care. Also, the sample only included those children who had not been looked after before. Hence the problems reported in this study were clearly not caused or directly influenced by the care process. Further work is necessary to investigate how mental health and well-being change during the time in care and what influences and processes are involved in any change.

As mentioned previously, the children in the present study were still in care twelve months after entry - a longer period than usual. This suggests that they may have differed from those in the ONS sample (Meltzer et al., 2003) and this in part could account for the greater incidence of problems identified in the present study. It is possible that those with greater emotional, behavioural or mental health problems remain looked after for longer.

The incidence of bedwetting reported here (17.9\%) is similar to that $(16 \%)$ observed by Meltzer et al. (2003) in their study of looked after children. This may therefore represent a reliable assessment of the extent of the problem 
and may also provide an indication of the reliability of the reporting of such problems in case files.

The prevalence of bedwetting was high among older children and young people looked after and appeared to be associated with evidence of abuse in those aged 11 to 15 . It has been previously reported that bedwetting is associated with becoming looked after, especially in older children. In these children bedwetting tends to be secondary (occurring after an absence of at least six months) and is associated with a higher incidence of parental separation, parental disharmony, and the early separation of child and parent (Butler, 1994; Jarvelin, Moilanen, Vikavainen-Tervonen, \& Huttunen, 1990; Kalo \& Bella, 1996; von Gontard et al., 1997). Also, those over four years of age with nocturnal enuresis appear at an increased risk of behavioural and emotional problems (Liu, Sun, Uchiyama, Li, \& Okawa, 2000) and children aged between five and 11 with voiding postponement exhibit significantly more conduct disorder (von Gontard et al., 1998). The present study suggests that bedwetting may also be indicative of abuse or neglect in older children (see also Mannarino \& Cohen, 1986, who found an association between sexual abuse and enuresis). The high prevalence makes it pertinent to consider any particular issues which bedwetting may raise for looked after children and young people. For example, it has been reported that bedwetting may cause children to experience perplexity, humiliation, social isolation, a fear of detection and a sense of immaturity (Anon., 1987; Butler, 1987, 1994). This may have particular significance for those looked after. In residential care children and young people live in very close proximity to their peers, 
maintaining secrecy may be difficult and the humiliation of being found out may be particularly cruel. In foster care, children and young people with enuresis may be apprehensive of the response of their carer, and even if they are placed with their parents or relatives they may fear the consequences of detection. The issue of bedwetting may therefore warrant special attention among those looked after (See Butler, 2004 for a review of the types of children who wet the bed and the impact of bedwetting upon them).

Analysis of the placement data shows that there is a greater likelihood for children who have conduct problems to be placed in residential care. Our sample included nine boys aged 5-10 years in such care. It has been suggested that boys exhibiting conduct disorder in childhood are fundamentally different from those who develop conduct disorder in adolescence; early onset conduct disorder may be associated with greater levels of violence and poorer outcomes (Loeber, Green, Lahey, Frick, \& McBurnett, 2000; McCabe, Hough, Wood, \& Yeh, 2001; Moffit, 1993). Findings from this study show that a challenging group of younger, very troubled children are being placed in residential care, an environment which may be inappropriate both in terms of their age and their needs. There is evidence that the use of such placements may reflect the necessity of finding accommodation rather than an attempt at dealing with these children's underlying problems; certainly these placements often result in unsatisfactory outcomes (Sinclair \& Gibbs, 1998). There have been suggestions that specialist foster care placements may be more beneficial to these young people (Polnay, Glaser, \& Dewhurst, 1997); to this end, multi-dimensional 
treatment foster care, following the Oregon model, is currently being piloted in England $^{1}$. Certainly, it is of particular importance to offer appropriate services to boys who exhibit conduct disorder prior to adolescence as developmental trajectories suggest that this group is at a particular risk of committing violent offences (Loeber et al., 2000; Minty, 1988) in the future. These data indicate the importance of undertaking a thorough assessment of children and young people's emotional and behavioural development and needs prior to placement.

\section{Conclusion}

The findings from this study highlight the prevalence of a number of different emotional needs at the point of entry into care of children and young people with no previous history of care. Such needs cannot be attributed to the care system itself. A greater incidence of problems was identified in the present study than has been previously reported. Although the nature of the sample and the methodology used in the present work differed from that of previous studies, the possibility remains that the level of mental health needs of looked after children and young people may be underestimated. Further research may elucidate this issue. Additionally, this study has shown that many children under five who are looked after may also have developmental problems indicative of emotional and behavioural difficulties. It is often assumed that such high levels of need are the result of children's adverse experiences in care, however, the children in this study had no previous experience of care

\footnotetext{
${ }^{1}$ The Evaluation of Multi-dimensional Treatment Foster Care in England (MTFCE), a study by the Universities of York and Manchester and funded by the DfES.
} 
and were assessed at entry to the care system and their difficulties, therefore, will reflect adverse experiences in the home environment. Whatever the aetiology, this study demonstrates high levels of emotional and behavioural disturbance within the care population. Such needs cannot be adequately addressed without long-term specialist support. The type of problems encountered by children and young people in this study indicates a need for a highly trained workforce able to provide wraparound services for children wherever they are placed and for a service that continues beyond the placement and follows the child. Care Matters: Time for Change (Department for Education and Skills, 2007) promises a number of national initiatives to help equip carers to respond appropriately to the needs of looked after children, with a strong emphasis on improving their capacity to respond appropriately to emotional and behavioural problems. There are plans to fund 'improved training of foster carers to develop their capacity to use positive parenting techniques to manage difficult and challenging behaviour' (pp. 5152). There are also plans to continue piloting Multi-dimensional Treatment Foster Care (now extended to younger children) and to fund a pilot programme to evaluate the effectiveness of social pedagogy in residential care (p. 58). All of these initiatives should improve the ability of the workforce to respond to the types of behaviour patterns so evident in the sample of children discussed in this paper. 
Table 1. The incidence of mental and behavioural problems in five to 15 year olds in the general population (Meltzer et al., 2000), in those looked after (Meltzer et al., 2003) and at point of entry into care or accommodation (present study, children with no previous history of care).

\begin{tabular}{|l|c|c|c|}
\hline $\begin{array}{l}\text { Mental and behavioural } \\
\text { disorder or problem }\end{array}$ & $\begin{array}{c}\% \\
\begin{array}{c}\text { General } \\
\text { children } \\
\text { (Meltzer } \\
\text { et al., } \\
2000)\end{array}\end{array}$ & $\begin{array}{c}\% \\
\text { Looked } \\
\text { after } \\
\text { children } \\
\text { (Meltzer } \\
\text { et al., } \\
2003)\end{array}$ & $\begin{array}{c}\% \\
\text { Looked } \\
\text { after } \\
\text { children } \\
\text { (present } \\
\text { study) }\end{array}$ \\
\cline { 1 - 1 } $\begin{array}{l}\text { Emotional disorder/problem } \\
\begin{array}{l}\text { Conduct disorder/problem } \\
\text { Any mental or behavioural } \\
\text { disorder or problem }\end{array}\end{array}$ & 5 & 12 & $\mathbf{2 3}$ \\
\cline { 1 - 2 }$n$ & 10 & 46 & $\mathbf{5 0}$ \\
\hline
\end{tabular}


Table 2. The effect of age and gender on the prevalence of emotional and conduct disorder and problems in the general population (Meltzer et al., 2000), in those looked after (Meltzer et al., 2003) and at point of entry into care or accommodation (present study, children with no previous history of care).

\begin{tabular}{|c|c|c|c|c|c|c|c|}
\hline \multicolumn{2}{|c|}{$\begin{array}{rr} & \text { Gender }\end{array}$} & \multicolumn{3}{|c|}{ Boys } & \multicolumn{3}{|c|}{ Girls } \\
\hline \multicolumn{2}{|l|}{$\%$ of children with } & $0-4$ & $5-10$ & 11-15 & $0-4$ & $5-10$ & 11-15 \\
\hline \multirow[t]{4}{*}{$\begin{array}{l}\text { Emotional } \\
\text { Disorders/Problems }\end{array}$} & $\begin{array}{l}\text { General population } \\
\text { (Meltzer et al., 2000) }\end{array}$ & - & 3.3 & 5.1 & - & 3.3 & 6.1 \\
\hline & $\begin{array}{l}\text { Looked after children } \\
\text { (Meltzer et al., 2003) }\end{array}$ & - & 13.4 & 8.4 & - & 9.0 & 16.1 \\
\hline & $\begin{array}{l}\text { Looked after children } \\
\text { (present study) }\end{array}$ & 6.4 & 17.7 & 20.3 & 3.5 & 22.2 & 33.3 \\
\hline & $n$ (present study) & 109 & 79 & 74 & 86 & 36 & 60 \\
\hline \multirow[t]{4}{*}{$\begin{array}{l}\text { Conduct } \\
\text { Disorders/Problems }\end{array}$} & $\begin{array}{l}\text { General population } \\
\text { (Meltzer et al., 2000) }\end{array}$ & - & 6.5 & 8.6 & - & 2.7 & 3.8 \\
\hline & $\begin{array}{l}\text { Looked after children } \\
\text { (Meltzer et al., 2003) }\end{array}$ & - & 44.0 & 45.4 & - & 27.4 & 34.5 \\
\hline & $\begin{array}{l}\text { Looked after children } \\
\text { (present study) }\end{array}$ & 11.0 & 57.0 & 54.1 & 2.3 & 22.2 & 51.7 \\
\hline & $n$ (present study) & 109 & 79 & 74 & 86 & 36 & 60 \\
\hline \multirow{4}{*}{$\begin{array}{l}\text { Any emotional or } \\
\text { behavioural } \\
\text { problem or disorder }\end{array}$} & $\begin{array}{l}\text { General population } \\
\text { (Meltzer et al., 2000) }\end{array}$ & - & 10.4 & 12.8 & - & 5.9 & 9.6 \\
\hline & $\begin{array}{l}\text { Looked after children } \\
\text { (Meltzer et al., } 2003\end{array}$ & - & 49.6 & 54.7 & - & 33.4 & 42.8 \\
\hline & $\begin{array}{l}\text { Looked after children } \\
\text { (present study) }\end{array}$ & 19.3 & 77.2 & 75.7 & 17.4 & 58.3 & 70.0 \\
\hline & $n$ (present study) & 109 & 79 & 72 & 86 & 36 & 60 \\
\hline
\end{tabular}

(For clarity, values of $n$ are only included for the present study; refer to published studies for other values). 
Table 3. The effect of age and gender on the prevalence of bedwetting in looked after children (Meltzer et al., 2003) and at point of entry into care or accommodation (present study, children with no previous history of care).

\begin{tabular}{|l|c|c|c|c|c|c|}
\hline \multicolumn{1}{r|}{ Gender } & \multicolumn{3}{c|}{ Boys } & \multicolumn{3}{c|}{ Girls } \\
\hline \multicolumn{1}{|c|}{ Age } & $\mathbf{0 - 4}$ & $\mathbf{5 - 1 0}$ & $\mathbf{1 1 - 1 5}$ & $\mathbf{0 - 4}$ & $\mathbf{5 - 1 0}$ & $\mathbf{1 1 - 1 5}$ \\
\hline $\begin{array}{l}\text { \% children bedwetting } \\
\text { (present study) }\end{array}$ & 7.4 & 24.1 & 13.9 & 5.8 & 19.4 & 16.7 \\
\hline $\boldsymbol{n}$ present study & 108 & 79 & 72 & 86 & 36 & 60 \\
\hline $\begin{array}{l}\text { \% children bedwetting } \\
\text { (Meltzer et al, 2003) }\end{array}$ & - & 21 & 16 & - & 18 & 9 \\
\hline
\end{tabular}




\section{References}

Anon. (1987). My enuresis. Archives of Disease in Childhood, 62, 866-868.

Butler, R. J. (1987). Nocturnal enuresis: Psychological perspectives, Bristol: John Wright and Son.

Butler, R. J. (1994). Nocturnal enuresis: The child's experience. Oxford: Butterworth Heinemann.

Butler, R. J. (2004). Childhood nocturnal enuresis: Developing a conceptual framework. Clinical Psychology Review, 24, 909-931.

Department for Children, Schools and Families. (2007). The Integrated Children's System. http://www.everychildmatters.gov.uk/ics/

Department for Education and Skills. (2004). Every Child Matters: Change for Children. Nottingham: DfES Publications.

Department for Education and Skills. (2007). Care Matters: Time for Change, Cm7137. London: The Stationery Office.

Department of Health. (1995). Looking after children: Assessment and action records, essential information records, care plans, placement plans and review forms. London: HMSO. 
Department of Health. (2001). Children in need in England: Results of a survey of activity and expenditure as reported by local authority social services children and families teams for a survey week in February 2000. London: Department of Health.

Department of Health. (2002). Promoting the health of looked after children. London: Department of Health.

Frame, L. (2002). Maltreatment reports and placement outcomes for infants and toddlers in out-of-home care. Infant Mental Health Journal, 23 (5), 517540.

HM Treasury. (2003). Every Child Matters. London: The Stationery Office.

Jackson, S. (2001). The education of children in care. In S. Jackson (Ed.), Nobody ever told us school matters: Raising the educational attainments of children in care (pp 11-53). London: British Agencies for Adoption and Fostering.

Jackson, S. and Thomas, N. (1999). On the move again? What works in creating stability for Looked After Children. Ilford: Barnardos.

Jarvelin, M. R., Moilanen, I., Vikevainen-Tervonen, L. and Huttunen, H. P. (1990). Life changes and protective capacities in enuretic and non-enuretic children. Journal of Child Psychology and Psychiatry, 31, 763-774. 
Kalo, B. B. and Bella, H. (1996). Enuresis: Prevalence and associated factors among primary school children in Saudi Arabia. Acta Paediatrica, 85, 12171222.

Liu, X., Sun, Z., Uchiyama, M., Li, Y. and Okawa, M. (2000). Attaining nocturnal urinary control; nocturnal enuresis and behavioural problems in Chinese children aged 6 through 16 years. Journal of the American Academy of Child \& Adolescent Psychiatry, 39, 1557-1564.

Loeber, R., Green, S. M., Lahey, B. B., Frick, P. J. and McBurnett, K. (2000). Findings on disruptive behaviour disorders from the first decade of the developmental trends study. Clinical Child and Family Psychology Review, 3 (1), 37-60.

Mannarino, A. P. and Cohen, J. A. (1986). A clinical-demographic study of sexually abused children. Child Abuse and Neglect, 10 (1), 17-23.

McCabe, K. M., Hough, R., Wood, P. A. and Yeh, M. (2001). Childhood and adolescent onset conduct disorder: A test of the developmental taxonomy. Journal of Abnormal Child Psychology, 29 (4), 305-316.

Meltzer, H., Corbin, T., Gatward, R., Goodman, R. and Ford, T. (2003). The mental health of young people looked after by local authorities in England. London: The Stationery Office. 
Meltzer, H., Gatward, R., Goodman, R. and Ford, T. (2000). Mental health of children and adolescents in Great Britain. London: The Stationery Office.

Minty, B. (1988). Public Care or Distorted Family Relationships: The Antecedents of Violent Crime. Howard Journal of Criminal Justice, 27 (3), 172-187.

Moe, V. and Slinning, K. (2002). Prenatal drug exposure and the conceptualisation of long-term effects. Scandinavian Journal of Psychology, 43, 41-47.

Moffit, T. E. (1993). Adolescence-limited and life-course-persistent antisocial behaviour: A developmental taxonomy. Psychological Review, 4, 674-701.

National Children's Bureau. (2005). Healthy Care Training Manual: A health promotion training programme for foster carers and residential social workers. London: National Children's Bureau.

Packman, J. and Hall, C. (1998). From care to accommodation: Support, protection, and control in child care services. London: The Stationery Office.

Polnay, L., Glaser, A. W. and Dewhurst, T. (1997). Children in residential care; what cost? Archives of Diseases in Childhood, 77, 394-395. 
Quinton, D. and Murray, C. (2002). Assessing emotional and behavioural development in children looked after away from home. In H. Ward and W. Rose. (Ed.) Approaches to needs assessment in children's services. London: Jessica Kingsley Publishers.

Selwyn, J., Sturgess, W., Quinton, D. and Baxter, C. (2003). Costs and outcomes of non-infant adoptions. Bristol: Bristol University, School of Policy Studies.

Sinclair, I. and Gibbs, I. (1998). Children's homes: A study in diversity. Chichester: Wiley.

Skuse, T., Macdonald, I. and Ward, H. (2001). Looking after children: Transforming data into management information, report of longitudinal study at 30.9.99. Third interim report to the Department of Health. Loughborough: Loughborough University, Centre for Child and Family Research.

Skuse, T. and Ward, H. (2003). Outcomes for looked after children: Children's views of care and accommodation. An interim draft report for the Department of Health. Loughborough: Loughborough University, Centre for Child and Family Research.

Stanley, N., Riordan, D. and Alaszewski, H. (2005). The mental health of looked after children: Matching response to need. Health and Social Care in the Community, 13, (3), $239-248$. 
von Gontard, A., Hollman, E., Eiberg, H., Benden, B., Rittig, S. and Lehmkuhl, G. (1997). Clinical enuresis phenotypes in familial nocturnal enuresis. Scandinavian Journal of Urology and Nephrology, 31 (Suppl. 183), 11-16.

von Gontard, A., Lettgen, B., Olbing, H., Heiken-Lowenau, C., Gaebel, E. and Schmitz, I. (1998). Behavioural problems in children with urge incontinence and voiding postponement. British Journal of Urology, 81 (Suppl. 3), 100-106.

Ward, H. (1995). (Ed.) Looking after children: Research into Practice. London: The Stationery Office.

Ward, H. (2004). Working with managers to improve services: Changes in the role of research in social care. Child and Family Social Work, 9 (1), 13-25.

Ward, H., Holmes, L., Soper, J. and Olsen, R. (Forthcoming). Outcomes for looked after children: Costs and consequences of placement choice. London: Jessica Kingsley Publishers.

Ward, H., Jones, H., Lynch, M. and Skuse, T. (2002). Issues concerning the health of looked after children. Adoption and Fostering, 26 (4), 8-18. 
Ward, H., Munro, E. and Dearden, C. (2006). Babies and young children in care: Life pathways, decision-making and practice. London: Jessica Kingsley Publishers.

Ward, H. and Skuse, T. (1999). Looking after children: Using data as management information, report from the first year of data collection. Report to the Department of Health. Totnes: Dartington Research Unit. 